\title{
DA LIBERDADE DE EXPRESSÃO AO DIREITO À COMUNICAÇÃO
}

\author{
GUSTAVO FERREIRA SANTOS*
}

\begin{abstract}
RESUMO: O presente trabalho reflete sobre os principais problemas envolvendo a garantia de direitos fundamentais em matéria de comunicação social. Para isso, compara posições liberais contrárias à intervenção estatal e posições favoráveis a uma maior participação do Estado na regulação dos meios de comunicação.

PALAVRAS-CHAVE: Liberdade de Expressão; Regulação da Comunicação Social; Democracia.
\end{abstract}

ABSTRACT: This paper reflects on the key issues involving the guarantee of fundamental rights on the media. For this, it compares positions against any intervention of the state and positions for a greater participation of the state in the regulation of the media.

KEYWORDS: Freedom of Expression; Regulation of the Media; Democracy.

Vivemos uma época marcada por um destaque especial dos meios de comunicação na vida social. Além dos clássicos meios, surgem cotidianamente novas possibilidades de comunicação. $\mathrm{O}$ alcance dos meios coloca hoje problemas que não podem ser resolvidos com os velhos parâmetros cunhados em tempos nos quais a imprensa tinha dimensões mais modestas. Uma das questões mais importantes é dimensionar as conseqüências das normas constitucionais que tocam a comunicação.

Basicamente, duas posições disputam os rumos da interpretação da regulação constitucional da comunicação social. De um lado, há uma posição que tem por principal preocupação a liberdade individual. Com um colorido liberal, preocupando-se com a autonomia do indivíduo. Para tal posição, quanto menos atividade estatal melhor. De outro lado, há os que se preocupam com a produção de um espaço no qual as opiniões serão apresentadas, com garantias de oportunidades para os diversos grupos que disputam o poder. Para essa posição, a regulação estatal é justificável em relação a alguns problemas.

Essas duas são matizadas, existindo, nos dois campos, posicionamentos mais radicais.

Artigo recebido em 13.01.2010 e aprovado para publicação pelo Conselho Editorial em 30.03.2010.

* Professor Adjunto da Universidade Federal de Pernambuco e da Universidade Católica de Pernambuco. Atua nos programas de pós-graduação em Direito das duas instituições, orientando mestrandos e doutorandos. Coordenador Adjunto da Área de Direito na Coordenação de Aperfeiçoamento de Pessoal de Nível Superior - CAPES (2008-2010). 
Do lado dos opositores da regulação, há posicionamentos libertários, como, por exemplo, o de Raoul Vaneigen, que defende o fim de qualquer limitação à liberdade de expressão. Não seriam passíveis de restrição nem mesmo os discursos ofensivos ao indivíduo, tradicionalmente criminalizados, com tipos como injúria, calúnia e difamação. Todos os excessos do discurso seriam resolvidos com mais discurso.

Do lado dos defensores da regulação, há posicionamentos voluntaristas e instrumentais, que vêm a intervenção como forma de transformar os meios em auxiliares de uma luta por uma tipo de sociedade e de calar posicionamentos incovenientes. Esse tipo de posicionamento está subjacente em discursos de algumas posições políticas de esquerda.

Aqui, vou trabalhar com posicionamentos moderados, dos dois lados, que são enquadráveis na tradição da democracia constitucional. Owen Fiss localiza as duas propostas na tradição liberal.

O discurso da auto-regulação é característico do grupo que teme o Estado. Como é conveniente às empresas de comunicação, que têm o grande poder de comunicar a longo alcance, essa posição hoje é a mais difundida no país. Empresas e empresários fomentam um discurso de que dar ao Estado o poder de regular a mídia sempre resultaria em censura. Utilizam a "liberdade de expressão" como álibi para atingir seus interesses marcadológicos. Agem como se fossem donos do discurso da "liberdade de expressão".

Os inimigos da regulação falam, sempre, em nome das liberdades. No entanto, deixam de reconhecer que as modernas democracias constitucionais funcionam buscando um equilíbrio entre "liberdades liberais" e "liberdades democráticas" (BOVERO, 2002). Não se trata apenas de garantir, por meio de uma Constituição, espaços livres ao indivíduo, nos quais eles possam atuar sem constrangimentos externos - objetivo das liberdades herdadas do constitucionalismo liberal. É necessário que seja garantida a igual participação desses indivíduos na formação da vontade geral, nas decisões sobre negócios públicos. Muitas vezes, é mais ameaçador a essa autonomia política a manipulação da informação e da opinião do que qualquer constrição explícita.

Michelangelo Bovero questiona até que ponto estamos seguros de que nossa vontade política é autônoma, independente do poder-querer de alheio, afirmando:

Refiro-me nem tanto ao poder que condiciona o agir, impedindo e coagindo, proibindo e obrigando", mas ao poder que condiciona a vontade, fornecendo informações parciais ou deformadas, apresentando problemas em termos distorcidos, não apresentando outros problemas tão ou mais relevantes, sugerindo critérios de juízo inadequados ou de alguma forma maquiados; em suma, fazendo-nos olhar através de lentes deformadoras que nos impedem de ver corretamente a realidade, de julgar com ponderações, de decidir com a nossa própria cabeça, em uma palavra, de querer autonomamente. (2002, p. 91)

Uma democracia precisa garantir a liberdade de expressão. Esse poder individual de manifestar sem constrangimentos externos a opinião está ligado ao direito fundamental 
à participação no processo democrático. Vedações ao discurso podem significar desequilíbrios na disputa política. Por isso, devem ser vistas sempre com desconfiança.

Essa é o pano de fundo do dilema em torno da regulação do “discurso do ódio”. $\mathrm{Na}$ Alemanha, que sofreu fortemente as conseqüências de um discurso político manipulador, mais facilmente se justifica a proibição do discurso que fomenta o ódio, o que resulta, por exemplo, na criminalização do uso da suástica. Nos EUA, há uma dificuldade maior da aceitação da vedação. No entanto, a história do tratamento jurisdicional do tema demonstra um abandono gradual da posição que absolutiza a liberdade. Decisões sobre a cerimônia da queima da cruz, levadas a cabo pela Ku Klux Klan, mostram isso.

A discussão sobre a regulação do discurso de incitação ao ódio é apenas uma faceta de um problema maior que, para usar uma expressão de Owen Fiss (2005), é o "efeito silenciador do discurso". O discurso pode impedir outros discursos, havendo certas formas de discurso que precisam ser contidas em seus excessos pelo Estado.

Muito do nosso debate constitucional sofre influência do debate norte-americano sobre a primeira emenda, que determina que o Congresso não edite leis limitando a liberdade de expressão e a liberdade de imprensa:

Congress shall make no law respecting an establishment of religion, or prohibiting the free exercise thereof; or abridging the freedom of speech, or of the press; or the right of the people peaceably to assemble, and to petition the government for a redress of grievances.

Transferimos para nosso sistema a versão mais liberal da leitura desse dispositivo, que parece absolutizar a liberdade, em detrimento de outros direitos e interesses constitucionalmente protegidos. Mas temos uma estrutura constitucional que não só permite como parece determinar o exercício da regulação.

Um campo que exige uma regulação estatal e que a Constituição de 1988 assumiu como importante é da regulação da propriedade dos meios de comunicação. A regra com a proibição de monopólios é uma das mais importantes dentre as formas de intervenção estatal em matéria de comunicação. Ela está no art. 220:

\section{Art. 220.(...)}

$\S 5^{\circ}$. Os meios de comunicação social não podem, direta ou indiretamente, ser objeto de monopólio ou oligopólio.

Aparentemente é a mesma regulação que se faz em atividades econômicas, buscando evitar a concentração. No entanto, há diferenças fundamentais entre as duas formas de intervenção, que decorrem dos próprios motivos que as justificam. Enquanto a regulação econômica da concorrência busca garantir as posições dos outros participantes do mercado, na regulação da propriedade das mídias a preocupação vai além, alcançando os vínculos entre a livre circulação da informação e a democracia.

A possibilidade da concentração é uma constante ameaça à democracia, já que uma determinada posição política pode ter desproporcional poder no mercado de ideias. 
Quanto mais pulverizada a propriedade dos meios, mais os órgãos refletirão, em tese, a pluralidade que marca a sociedade.

A situação do Brasil nessa área é de falta de regra e alta concentração:

"Em 2002, 58,7\% das verbas de publicidade foram para a televisão aberta (Castro, Folha de S.Paulo, 10.03.2003). Do total gasto, em 2001, 78\% foram para a Globo e suas afiliadas (Castro, Folha de S.Paulo, 06.03.2002)”. (Lima)

Além desse fenômeno de concentração, há outro grave problema no Brasil, que é a promiscuidade entre meios de comunicação e agentes políticos. Um grande número de repetidoras de TV e de emissoras de rádio está em poder de detentores de mandatos eletivos ou de seus familiares. Isso causa uma grave distorção nos processos eleitorais, já que essas pessoas têm evidentes vantagens no embate de idéias que deveria caracterizar uma campanha. Porém, o mais grave é que isso reduz perspectivas de uma reforma legislativa constitucionalmente adequada.

Até nos EUA a propriedade dos meios já alcançou um alto grau de regulação, tendo passado por um processo de desregulamentação com a doutrina Bush, durante a administração do Michel Powell, filho do Colin Powell, na Federal Communications Commission (FCC).

Regular a propriedade dos meios de comunicação, evitando os monopólios, não representa qualquer ameaça à democracia, pelo contrário, é condição para que ela se desenvolva.

Essa atuação de controle da propriedade é importante, inclusive para evidenciar a falta, no Brasil de uma política de respeito à radiodifusão comunitária. Rádios e TVs comunitárias podem representar a realização dos princípios contidos no art. 221 da Constituição, em especial o do inciso II, que determina a "promoção da cultura nacional e regional e estímulo à produção independente que objetive sua divulgação".

A legislação atual é excessivamente restritiva e a condução dos processos administrativos que avaliam pedidos de novas rádios comunitárias é lenta e pouco transparente, o que tem levado iniciativas reais de radiodifusão comunitária à clandestinidade. Associam-se o aparato repressivo do Estado e a grande mídia na caça das rádios não-autorizadas.

As razões que justificam a imposição de limites às instituições midiáticas podem, no entanto, sustentar intervenções estatais que sufoquem a livre circulação da informação e a livre manifestação do pensamento. Existem estratégias de contenção dos excessos dos meios de comunicação que não passam pela outorga ao Estado de poderes especiais. Nesse sentido, é importante destacar os chamados MAS (media accountability systems).

Segundo Claude-Jean Bertrand (2002, p. 35), pode-se chamar de MAS “quaisquer meios de melhorar os serviços de mídia ao público, totalmente independentes do governo". Incluem-se nesse conceito instituições voltadas a discutir a qualidade da mídia - por exemplo, o Observatório da Imprensa - um ombusdman, uma agência independente de regulação do jornalismo, comitês de ética, dentre outros. 
Dessa forma, queremos finalizar destacando que discutir a liberdade de expressão será sempre uma tarefa dos democratas. Mas falar somente em liberdade de expressão com um olhar liberal é insuficiente, já que precisamos democratizar o acesso aos meios, acabando com o muro que divide a sociedade entre os que falam e os que gritam.

\section{REFERÊNCIAS}

BERTRAND, Claude-Jean. O Arsenal da Democracia: Sistemas de Responsabilização da Mídia. São Paulo: Universidade do Sagrado Coração, 2002.

FISS, Owen M. A Ironia da liberdade de expressão: estado, regulação e diversidade na esfera pública. Rio de Janeiro: Renovar, 2005.

VANEIGEM, Raoul. Nada é sagrado, tudo pode ser dito - reflexões sobre a liberdade de expressão. São Paulo: Parábola, 2004.

LIMA, Venício. Existe concentração na mídia brasileira? Sim. Observatório da Imprensa. $1^{\circ} .07 .2003$. Disponível em <http://www.observatoriodaimprensa.com.br/artigos/plq010720031.htm> Acesso em 15 out. 2009. 